\title{
PET-SAÚDE: POSSIBILIDADES E LIMITAÇÕES DO GRUPO DE TRABALHO E HUMANIZAÇÃO EM UNIDADE BÁSICA DE SAÚDE
}

\author{
Eliane Cristina de Andrade Gonçalves ${ }^{1}$ \\ Fernanda Quaglia Franzini² \\ Natália Aparecida Barzaghi ${ }^{3}$ \\ Lucia Cecilia da Silva ${ }^{4}$ \\ Diego Augusto Santos Silva
}

GONÇALVES, E. C. de A.; FRANZINI, F. Q.; BARZAGHI, N. A.; SILVA, L. C. da; SILVA, D. A. S. PET-SAÚDE: possibilidades e limitações do grupo de trabalho e humanização em unidade básica de saúde. Arq. Cienc. Saúde UNIPAR, Umuarama, v. 18, n. 3, p, 205207, set./dez. 2014.

\begin{abstract}
RESUMO: Essa experiência curricular inovadora foi desenvolvida na Universidade Estadual de Maringá e teve como objetivo relatar a experiência do PET-SAÚDE com o Grupo de Trabalho de Humanização de uma Unidade Básica de Saúde. A coleta de dados aconteceu por meio da observação participante e pela leitura das atas das reuniões da (UBS). Discutiram-se as possibilidades e limitações de um grupo de trabalho de humanização, com profissionais da UBS por meio dos pressupostos da Política Nacional de Humanização. O grupo de trabalho de humanização chegou aos seguintes resultados: há desconhecimento por parte dos servidores sobre o que é o Grupo de Trabalho de Humanização; há desqualificação das opiniões dos mesmos por conta da direção; há falta de representantes de todas as categorias profissionais; o grupo é gerador de ideias para a melhoria dos serviços oferecidos na unidade.
\end{abstract}

PALAVRAS-CHAVE: Sistema Único de Saúde; Humanização da assistência; Atenção primária à saúde.

\section{PET-HEALTH: POSSIBILITIES AND WORKING GROUP ON LIMITATIONS AND HUMANIZATION BASIC HEALTH UNIT}

ABSTRACT: This innovative curricular experience was developed at the State University of Maringá and aimed at reporting the experience of a group of students with the Work Group for the Humanization of the Basic Health Unit. Data collection occurred through participant observation and through the reading of meeting minutes. The possibilities and limitations of a humanization work group was discussed with UBS professionals based on the assumptions of the National Policy on Humanization. The data collected were analyzed and listed in accordance with possible actions and limits of the humanization work group, reaching the following results: most civil servers are unaware of the Humanization Work Group; their opinions are disqualified by the management; there is a lack of representatives from all professional categories; the group generates ideas for improving the services offered in the unit.

KEYWORDS: Health Care System; Humanization of assistance; Primary health care.

\section{Introdução}

Foi publicada em 2004 a Política Nacional de Humanização (PNH) (BRASIL, 2004). A partir de então, a humanização passa a ser entendida não só como um conteúdo de um programa isolado dentro da política transversal do Sistema Único de Saúde (SUS), mas também como um estilo de cuidado centrado na voz do sujeito e no respeito à autonomia (FONTANA, 2010).

Em relação à gestão do trabalho, a $\mathrm{PNH}$ prevê a promoção de atividades com intuito de assegurar a participação dos trabalhadores nos processos de discussão e decisão referente a assuntos do processo de trabalho (BRASIL, 2004). Ao explicitar as estratégias para a implementação desta política, o Ministério da Saúde propõe dentre outras ações, a organização e fortalecimento dos Grupos de Trabalho de Humanização (GTH). Na cartilha específica sobre o assunto, o GTH é definido como dispositivo criado pela PNH para o SUS com objetivo de intervir na melhoria dos processos de trabalho e na qualidade da produção de saúde para todos. Além disso, o GTH pode ser instituído em qualquer instância do SUS e é integrado por pessoas interessadas em discutir os serviços prestados, a dinâmica das equipes de trabalho e as relações estabelecidas entre trabalhadores de saúde e usuários (BRASIL, 2006; SCHMIDT; DANTAS, 2006).

Uma das dificuldades encontradas para a implementação do SUS se refere à formação dos profissionais da área da saúde, que tem deixado a desejar, como encontrado em outro estudo (COTTA et al., 2006). No intuito de promover uma formação mais adequada a esse campo, aproximando a academia e o serviço, foi criado o Programa de Educação pelo Trabalho para a Saúde (PET-SAÚDE), uma parceria dos Ministérios da Saúde e da Educação com intuito de direcionar a formação de profissionais de saúde, dentre eles a Educação Física para conteúdos e ações no SUS. Um dos subgrupos do PET-SAÚDE da Universidade Estadual de Maringá (UEM), atuou em uma Unidade Básica de Saúde (UBS) parceira do projeto cuja atividade entre abril de 2010 a março de 2011, se consistiu na implementação e fomento de um grupo de trabalho de humanização. Neste artigo, tem-se como objetivo apresentar a experiência de um grupo de alunos do pet-saúde Maringá (PR) com o Grupo de Trabalho de Humanização de uma Unidade Básica de Saúde.

DOI: https://doi.org/10.25110/arqsaude.v18i3.2014.5197

${ }^{1}$ Mestranda em Educação Física. Universidade Federal de Santa Catarina, Programa de Pós-Graduação em Educação Física, Florianópolis, Santa Catarina, Brasil. Campus Universitário - Universidade Federal de Santa Catarina - Centro de Desportos, Departamento de Educação Física, Campus Universitário Trindade - Caixa Postal 476, CEP 88040-900 - Florianópolis, Santa Catarina, Brasil. Telefone (Fax): +55 48 37218562, E-mail: elianeandradegoncalves@ gmail.com

${ }^{2}$ Graduação em Psicologia. Universidade Estadual de Maringá. Maringá, Paraná, Brasil.

${ }^{3}$ Doutoranda em Psicologia. Universidade Estadual de Maringá. Maringá, Paraná, Brasil.

${ }^{4}$ Doutorado em Ciências. Universidade Estadual de Maringá. Maringá, Paraná, Brasil.

${ }^{5}$ Doutorado em Educação Física. Universidade Federal de Santa Catarina, Florianópolis, Santa Catarina, Brasil. 


\section{Material e Método}

A experiência aqui relatada se integra à modalidade de investigação de natureza qualitativa. Os recursos metodológicos foram observação participante, enquanto técnica para a coleta de dados, bem como a leitura das atas das reuniões, que também serviram como fonte de coleta. Por meio da observação participante, o pesquisador pode analisar a realidade social com a intenção de identificar possíveis tensões, conflitos e motivações para mudanças (QUEIROZ; VIANA, 1992).

A observação participante ocorreu em quinze reuniões do GTH realizadas na UBS, com participação intermitente de profissionais da enfermagem, odontologia, psicologia, farmácia, agentes comunitários de saúde (ACS), representante da gestão e auxiliares administrativos, com participação média de 10 membros em cada reunião. Os acontecimentos das reuniões foram anotados pelos alunos do PET num diário de campo, que serviu como fonte de dados. Além disso, após a participação nos grupos, todas as atas das reuniões foram cedidas para o PET-SAÚDE para servirem de fonte para uma análise sobre o resultado do GTH.

O PET-SAÚDE da UEM integrante dessa experiência inovadora era formado por acadêmicos do curso de Educação Física, Enfermagem, Farmácia, Psicologia e Medicina. O local onde se deu a experiência foi uma UBS do município de Maringá (PR) que abrange uma população com mais de trinta e cinco mil usuários, a qual conta com sete equipes de saúde da família totalizando 115 servidores, dentre os quais estão Médicos, Enfermeiros, Farmacêuticos, Odontólogos, Psicólogos e ACS.

Os dados foram organizados e discutidos tendo-se em vista os pressupostos da PHN.

\section{Desenvolvimento da Experiência}

Inicialmente, os alunos do PET-SAÚDE convidaram todos os funcionários da UBS a participarem do GTH. Confirmaram participação no GTH 35 funcionários que, a priori, estavam dispostos a compartilhar e sugerir ideias de humanização dentro da UBS. Porém, com o avanço das atividades apenas 15 funcionários aderiram às atividades e estavam interessados em melhorar a gestão e as condições de trabalho dentro da UBS. Dos 15 funcionários que permaneceram no GTH, a única profissional de Educação Física que trabalhava no Núcleo de Apoio à Saúde da Família e participava das reuniões da UBS aderiu ao GTH e colaborou bastante com o grupo. Essa participação do profissional de Educação Física serve de incentivo aos acadêmicos do curso de Educação Física que integram o PET-SAÚDE.

Neste mesmo período, houve a dificuldade em distinguir GTH de colegiado. O colegiado diz respeito à forma de gestão em que a direção é compartilhada por um conjunto de pessoas com igual autoridade, que reunidas, decidem sobre algum assunto dentro do ambiente de trabalho (BRASIL, 2006). O GTH, por sua vez, tem o objetivo de propiciar a democratização das relações de trabalho, concedendo voz aos setores que normalmente não teriam condições de superar as barreiras de hierarquia e competência técnica (BRASIL, 2006). Dessa forma, no GTH todos os trabalhadores têm igual direito de opinar e sugerir melhorias, além de possibilitar ao trabalhador expressar-se livremente sobre o processo de humanização no seu cotidiano profissional, proporcionar o surgimento de um clima organizacional adequado, construindo espaços dialógicos (BACKES; LUNARDI; LUNARDI, 2006).

Um dos assuntos bastante discutidos no GTH foi a retomada das reuniões gerais dentro da UBS. Essas reuniões pararam de acontecer devido a falta de participação e de interesse por parte dos funcionários da unidade. Chegaram-se à conclusão que esses encontros seriam uma forma de aproximação entre os funcionários, possibilitando um momento de socialização sobre o trabalho realizado, em que todos poderiam compartilhar suas dificuldades, desafios e procurar soluções para os problemas do serviço em saúde. A criação desse espaço pressupõe o diálogo como alternativa de uma relação de pessoa a pessoa, com centralidade no reconhecimento e valorização do potencial humano para a liberação da criatividade e liberdade na construção e transformação da realidade (FREIRE, 1996). Assim, o GTH organizou, opinou e sugeriu temas que poderiam ser abordados nessas reuniões. Após encaminhamentos, aconteceram três reuniões gerais no período que esse relato foi desenvolvido. Os principais temas abordados foram respectivamente: diretrizes e estratégias da PHN, visando apresentar o GTH para todos os funcionários; motivação e trabalho em equipe; e esclarecimentos sobre a reforma da estrutura física da UBS. Cada um desses três encontros terminou com uma pequena confraternização, realizada pelos próprios trabalhadores, possibilitando um momento aprazível e de descontração, com muita conversa fora dos assuntos de rotina das equipes, possibilitando assim indireta humanização do trabalho destes servidores (MATSUDA et al., 2007).

Ademais, no GTH surgiu a proposta de implantação de uma caixa de opiniões, objetivando a melhoria da comunicação entre usuário-servidor e entre os próprios servidores, a qual teve como resultado que das 84 opiniões anônimas colocadas na caixa, 44 eram sobre sugestões para o serviço na UBS, 28 eram sobre críticas, sete eram elogios e cinco reportavam sugestões e críticas simultaneamente.

Por meio da análise desses resultados percebe-se que a população tem também um grande interesse na melhoria do sistema, sendo que mais de $50 \%$ dos recados foram referentes a sugestões; principalmente em relação à contratação de funcionários e infraestrutura da UBS (Tabela 1) o que corrobora com outro estudo realizado (SILVEIRA; BALDACCI, 2006).

Tabela 1: Propostas para melhorias no serviço em saúde em fevereiro de 2011.

\begin{tabular}{lcc}
\hline Sugestões & $\mathrm{N}$ & $\%$ \\
\hline Contratação de funcionários & 20 & 38,46 \\
Infraestrutura & 16 & 30,77 \\
Atendimento preferencial & 05 & 9,66 \\
Agendamento & 03 & 5,77 \\
Outros* & 08 & 15,38 \\
\hline TOTAL & 52 & 100
\end{tabular}

*Este item refere-se a: cartazes de localização, punição ao usuário mal intencionado, mais humanidade por parte dos servidores, amor à profissão, ginástica laboral, biblioteca para os funcionários, repre- 
sentatividade de todas as categorias no GTH e organização da sala de espera da UBS.

Com relação às críticas (Tabela 2), o segundo maior alvo de bilhetes na caixa de sugestões, percebe-se que a maior porcentagem é referente ao agendamento de consultas, resultado semelhante a outro estudo (SOUZA; PINTO; FIGUEIREDO, 2010).

Tabela 2: Perfil das críticas em fevereiro de 2011.

\begin{tabular}{lcc}
\hline Críticas & $\mathrm{N}$ & $\%$ \\
\hline Agendamento & 15 & 46,88 \\
Atendimento & 11 & 34,37 \\
Banheiros & 02 & 09,37 \\
Outros* & 04 & 18,75 \\
\hline TOTAL & 32 & 100
\end{tabular}

*Falta de dedetização, resolutividade do conselho (não foi especificado se local ou municipal) e trabalhadores que saem de seus postos de trabalho.

Após a atividade do PET-SAÚDE da UEM como organizador e parceiro no GTH no período da atividade proposta, as reuniões do GTH se mantêm até o presente momento dentro da UBS e têm acontecido quinzenalmente. O grupo ainda não conta com a presença de todas as categorias de trabalhadores, pois falta a participação da classe médica e administrativa. O profissional de Educação Física continua firmemente participando do GTH com papel de liderança nas reuniões, o que demonstra que o profissional de Educação Física do setor saúde não precisa somente prescrever e orientar atividades físicas.

Uma das maiores dificuldades enfrentadas no GTH é a dificuldade e barreiras colocadas pela direção da UBS em não legitimar algumas decisões do grupo, como o agendamento de datas para a realização de eventos e outras atividades encaminhadas pelos integrantes do GTH.

\section{Considerações Finais}

Como em qualquer ambiente de trabalho, esta UBS também enfrenta problemas relativos ao ambiente físico, aos funcionários, à clientela e, principalmente, no tocante às relações interpessoais e comunicação. Prova disso foi o desabafo de alguns funcionários quando da realização das atividades do PET-SAÚDE junto à UBS. Assim, o GTH tem sido uma ferramenta importantíssima para proporcionar espaço aberto às discussões dos problemas e situações que ocorrem no cotidiano de trabalho da UBS e, consequentemente, aperfeiçoando as relações interpessoais e a qualidade do serviço em saúde. É um dispositivo que tem o potencial de gerar discussões e oferecer oportunidades de aprimoramento relacional e comunicacional, tanto entre os servidores como entre os servidores e usuários. Ademais, o profissional de Educação Física pode/deve estimular um ambiente de humanização na UBS

\section{Referências}

BACKES, D. S.; LUNARDI FILHO, W. D.; LUNARDI, V. L. O processo de humanização do ambiente hospitalar centrado no trabalhador. Rev Esc Enferm USP, v. 40, n. 2, p. 221-7, 2006.

BRASIL. Ministério da Saúde. Secretaria-Executiva. Núcleo Técnico da Política Nacional de Humanização

HumanizaSUS: política nacional de humanização: documento base para gestores e trabalhadores do SUS / Ministério da Saúde, Secretaria-Executiva, Núcleo Técnico da Política Nacional de Humanização. Brasília: Ministério da Saúde, 2004.

BRASIL. Ministério da Saúde. Secretaria-Executiva. Núcleo Técnico da Política Nacional de Humanização. Grupo de Trabalho de Humanização / Ministério da Saúde, Secretaria-Executiva, Núcleo Técnico da Política Nacional de Humanização. 2.ed. Brasília: Editora do Ministério da Saúde, 2006.

CASATE, J. C.; CORRÊA, A. K. Humanização do atendimento em saúde: conhecimento veiculado na literatura brasileira de enfermagem. Rev. Latino-Am. Enfermagem, v. 13, n. 1, p. 105-11, 2005.

COTTA, R. M. M. et al. Organização do trabalho e perfil dos profissionais do Programa Saúde da Família: um desafio na reestruturação da atenção básica em saúde. Epidemiol Serv Saúde, v. 15, n. 3, p. 7-18, 2006.

FONTANA, R. T. Humanização no processo de trabalho em enfermagem: uma reflexão. Rev Rene, v. 11, n. 1, p. 200-7, 2010.

FREIRE, P. Educação como prática da liberdade. 22. ed. Rio de janeiro: Paz e Terra: 1996. 81 p.

MATSUDA, L. M.; FONSECA, S. C.; TRIGO, I. M. R.; FEREL, S. M. O Cuidado de quem cuida: reflexões acerca da (des)humanização do enfermeiro. Nursing, v. 10, n. 109, p. $281-86,2007$.

QUEIROZ, M. S.; VIANNA, A. L. Padrão de política estatal em saúde e o sistema de assistência médica no Brasil atual. Rev de Saúde Pública, v. 26, n. 2, p. 132-40, 1992.

SCHMIDT, D. R. C.; DANTAS, R. A. S. Qualidade de vida no trabalho de profissionais de enfermagem, atuantes em unidades do bloco cirúrgico, sob a ótica da satisfação. Rev. Latino-Am. Enfermagem, v. 14, n. 1, p. 54-60, 2006.

SILVEIRA, M. G. G.; BALDACCI, E. R. Humanização e autogestão em uma unidade básica de saúde. Pediatria (São Paulo), v. 28, n. 4, p. 226-33, 2006.

SOUZA, M. F.; PINTO, I. C.; FIGUEIREDO, L. A. Análise da utilização do serviço de pronto-socorro na percepção do usuário. Cienc Cuid Saude, v. 9, n. 1, p. 13-20, 2010. 